\title{
Interactions Between Chill-Hours and Degree-Days Affect Carpogenic Germination in Monilinia vaccinii-corymbosi
}

\author{
H. Scherm, A. T. Savelle, and P. L. Pusey
}

First and second authors: Department of Plant Pathology, University of Georgia, Athens 30602; and third author: U.S. Department of

Agriculture, Agricultural Research Service, Tree Fruit Research Laboratory, Wenatchee, WA 98801.

Accepted for publication 22 September 2000.

\begin{abstract}
Scherm, H., Savelle, A. T., and Pusey, P. L. 2001. Interactions between chill-hours and degree-days affect carpogenic germination in Monilinia vaccinii-corymbosi. Phytopathology 91:77-83.

The relationship of cumulative chill-hours (hours with a mean temperature $<7.2^{\circ} \mathrm{C}$ ) and heating degree-days (base $7.2^{\circ} \mathrm{C}$ ) to carpogenic germination of pseudosclerotia of Monilinia vaccinii-corymbosi, which causes mummy berry disease of blueberry, was investigated. In two laboratory experiments, pseudosclerotia collected from rabbiteye blueberry in Georgia were conditioned at 5 to $6^{\circ} \mathrm{C}$ for 26 to $1,378 \mathrm{~h}$ prior to placement in conditions favorable for germination and apothecium development. The number of chill-hours accumulated during the conditioning period affected the subsequent proportion of pseudosclerotia that germinated and produced apothecia, with the greatest incidence of carpogenic germination occurring after intermediate levels of chilling ( $\approx 700$ chill-hours). The minimum chilling requirement for germination and apothecium production was considerably lower than that reported previously for pseudo-

between the accumulation of chill-hours and degree-days during the conditioning and germination periods; pseudosclerotia exposed to prolonged chilling periods, once transferred to suitable conditions, germinated and produced apothecia more rapidly (after fewer degree-days had accumulated) than those exposed to shorter chilling periods. Thus, pseudosclerotia of $M$. vaccinii-corymbosi are adapted to germinate carpogenically following cold winters (high chill-hours, low degree-days) as well as warm winters (low chill-hours, high degree-days). Results were validated in a combined field-laboratory experiment in which pseudosclerotia that had received various levels of natural chilling were allowed to germinate in controlled conditions in the laboratory, and in two field experiments in which pseudosclerotia were exposed to natural chilling and germination conditions. A simple model describing the timing of apothecium emergence in relation to cumulative chill-hours and degreedays was developed based on the experiments. The model should be useful for better timing of field scouting programs for apothecia to aid in management of primary infection by $M$. vaccinii-corymbosi.
\end{abstract} sclerotia from highbush blueberry in northern production regions. The rate of carpogenic germination was strongly affected by interactions
Additional keywords: thermal time, Vaccinium ashei.
Mummy berry disease is a key problem in the commercial production of blueberries (Vaccinium spp.) in North America $(3,12)$, including Georgia (27) and other parts of the southeastern United States (6). Monilinia vaccinii-corymbosi, the fungus that causes the disease, survives in infected, mummified fruit (pseudosclerotia) on the orchard floor. In late winter or early spring, pseudosclerotia germinate carpogenically, forming apothecia from which ascospores are released. Ascospores, the only primary inoculum, infect and blight young, expanding leaves and shoots $(3,4,15)$. Conidia formed on blighted tissue during spring cause secondary infections via the stigma and style of open flowers, followed by colonization of the locules of the developing fruit $(19,29)$. During the fruit maturation phase in early summer, further growth and development of $M$. vaccinii-corymbosi within infected berries leads to the formation of fruit mummies, which drop to the ground before or at harvest and serve as oversummering and overwintering structures.

Rabbiteye blueberries (Vaccinium ashei), which are native to the southeastern United States, comprise $>90 \%$ of the commercial acreage in Georgia. In contrast, most of the blueberry plantings in northern production regions consist of lowbush ( $V$. angustifolium and $V$. myrtilloides) or northern highbush (V. corymbosum) cultivars. The three blueberry species differ in growth habit, phenology, and other horticultural aspects $(2,30)$. Whereas the epidemiology of

Corresponding author: H. Scherm; E-mail address: scherm@uga.edu

Publication no. P-2000-1023-01R

This article is in the public domain and not copyrightable. It may be freely reprinted with customary crediting of the source. The American Phytopathological Society, 2001. mummy berry disease has been studied in detail on lowbush and highbush blueberries in the northern production regions of North America $(3,4,11,14-16,18,19,22,23)$, little research has been done on this disease on rabbiteye blueberry in the Southeast $(8,27)$.

Because apothecia formed on pseudosclerotia are the only source of primary inoculum $(3,4,12)$, the first appearance of apothecia in late winter or early spring represents a key epidemiological event in the mummy berry disease cycle. Field scouting of sclerotia or pseudosclerotia for stipes or apothecia has been suggested as a decision aid for the timing of management tactics against primary infection by closely related discomycetes, e.g., Sclerotinia sclerotiorum (1). In most rabbiteye blueberry plantings in Georgia, however, pseudosclerotia are present in low densities (H. Scherm and P. L. Pusey, unpublished data), rendering scouting during the entire potential apothecium emergence period too time-consuming for practical use. If conditions that favor germination could be ascertained and the timing of apothecium emergence predicted, scouting could be limited to those periods when apothecium emergence is most likely, thereby rendering the approach more feasible.

Carpogenic germination of pseudosclerotia of $M$. vacciniicorymbosi in relation to environmental conditions has been studied previously. Milholland $(18,19)$ reported that temperature, along with soil moisture, is a critical factor in the germination of pseudosclerotia and the subsequent development of apothecia. He showed that pseudosclerotia required a cold-temperature conditioning period of at least 900 to 1,200 chill-hours (number of hours with a mean temperature $<7.2^{\circ} \mathrm{C}$ ) before normal apothecium development could occur (19). This chill-hour range is very similar to that required for adequate bud break in northern highbush 
blueberry cultivars grown in southeastern North Carolina (where these studies were carried out), suggesting that the pathogen has adapted to resume activity in the spring concurrently with its host. The hypothesis of successful adaptation in the timing of apothecium development in $M$. vaccinii-corymbosi to the phenology of its host was supported by Bristow (5) who found that pseudosclerotia required $\approx 700$ chill-hours for carpogenic germination in the maritime climate of Washington State where the chilling requirement for commonly grown blueberry cultivars is lower than in North Carolina. Lehman and Oudemans $(14,16)$ described cultivar-specific adaptation in the phenology of M. vaccinii-corymbosi, whereby apothecia developed earlier on pseudosclerotia collected in plantings of early season highbush blueberry cultivars than on those collected in late season cultivars in New Jersey. It is unknown whether the apparent coevolution between the pathogen and its host can be substantiated in the commercial rabbiteye blueberry production regions of Georgia where the chill-hour requirement for commonly grown cultivars ranges from $<200$ to $800 \mathrm{~h}$ (2).

The objectives of this research were to (i) determine the chillhour requirement for carpogenic germination of pseudosclerotia of M. vaccinii-corymbosi from rabbiteye blueberry in Georgia; (ii) compare development times for the production of apothecia on early and late season rabbiteye blueberry cultivars; and (iii) develop a simple model to predict timing of apothecium emergence based on thermal time accumulated during the conditioning and germination periods. Preliminary accounts of parts of this work have been given $(26,28)$.

\section{MATERIALS AND METHODS}

Laboratory experiments. Pseudosclerotia were collected from the ground in a rabbiteye blueberry planting with a history of se-

TABLE 1. Description of five experiments in which the relationship of cumulative chill-hours and heating degree-days to subsequent germination and apothecium emergence of pseudosclerotia of Monilinia vaccinii-corymbosi was investigated

\begin{tabular}{llllllc} 
& & \multicolumn{2}{c}{ Chilling treatment } & & \multicolumn{2}{c}{ Germination treatment } \\
\cline { 5 - 6 } Exp. & Cultivar & Location & Chill-hours $^{\mathrm{a}}$ & & Location & Degree-days \\
\hline 1 & Climax & Laboratory & $26-1,344$ & & Laboratory & $202-772$ \\
2 & Climax & Laboratory & $34-1,378$ & & Laboratory & $229-713$ \\
3 & Mixed & Field & $21-429$ & & Laboratory & $652-1,022$ \\
4 & Climax & Field & $1,415^{*}$ & & Field & 258 \\
& Tifblue & & $1,465^{*}$ & & 272 \\
5 & Climax & Field & $1,393^{*}$ & & Field & 373 \\
& Tifblue & & $1,393^{*}$ & & 373 \\
\hline
\end{tabular}

a Chill-hours represent the number of hours with a mean temperature $<7.2^{\circ} \mathrm{C}$.

* Indicates number of chill-hours accumulated at which the proportion of pseudosclerotia with apothecia attained $25 \%$ of its maximum value.

b Degree-days calculated with hourly measurements of air temperature with a base of $7.2^{\circ} \mathrm{C}$. Accumulation of degree-days was initiated on the date when the first chill-hour was recorded. Values indicate number of degree-days accumulated at which the proportion of pseudosclerotia with apothecia attained $25 \%$ of its maximum value for each chilling treatment. vere mummy berry disease in Murray County in northern Georgia on 8 October 1997 and 19 October 1998 (experiments 1 and 2, respectively; Table 1). At the time of their collection, the pseudosclerotia had received an estimated 26 chill-hours in 1997 and 34 chill-hours in 1998, based on air temperatures measured at a nearby agrometeorological station (13). Pseudosclerotia were rinsed by shaking in distilled water containing $0.2 \mathrm{ml}^{-1}$ of Tween 80 for $20 \mathrm{~min}$, enclosed in fiberglass mesh bags in groups of 32, and either buried in saturated sand (23\% water content by weight) in a perforated plastic tray (treatment 1) or submerged in continuously aerated distilled water in a 4-liter beaker (treatment 2). In the latter treatment, which was included to enhance leaching of potential inhibitors of carpogenic germination, aeration was provided with an aquarium pump and bubble stone (9). The tray and beaker were placed in a refrigerated incubator $\left(5\right.$ to $\left.6^{\circ} \mathrm{C}\right)$ in darkness for 0, 336, 672, 1,008, or 1,344 h in 1997 and 0, 96, 336, 672, 1,008, or $1,344 \mathrm{~h}$ in 1998. During the conditioning period, the sand in treatment 1 was maintained at field capacity by placing the tray in a pan with distilled water; water in treatment 2 was replaced weekly.

At the conclusion of each chilling period, three bags with pseudosclerotia were recovered from each of the two treatments. Pseudosclerotia were removed from the bags and transferred onto sand maintained at field capacity in 10.2-cm-diameter plastic pots; all pseudosclerotia from a given bag were placed in the same pot. To induce carpogenic germination, pots were moved into a second incubator (referred to as the "germination chamber") set at 16 to $17^{\circ} \mathrm{C}$ with $>80 \%$ relative humidity and a 14 -h photoperiod provided by fluorescent plant growth lights (photon flux density 160 to $180 \mu \mathrm{mol} \mathrm{m} \mathrm{m}^{-2} \mathrm{~s}^{-1}$ ). Using a stereo microscope, pseudosclerotia were assessed in situ for the presence of stipes and apothecia at 2- to 4-day intervals over a period of at least 4 months in both experiments. Data were summarized for each pot as cumulative proportion of pseudosclerotia with stipes (referred to as "germinated pseudosclerotia") and as cumulative proportion of pseudosclerotia with apothecia. Means and standard errors of the two variables were computed and plotted against the number of chill-hours accumulated during the conditioning period (included natural chilling received prior to collection of pseudosclerotia in the field). This was done with combined data from the chilling treatments in saturated sand and aerated water after an analysis of variance showed no significant differences between these two treatments (Table 2).

For each of the chilling periods, the final cumulative proportion of pseudosclerotia with apothecia $\left(p_{\max }\right)$ was noted. Based on progress curves describing the cumulative proportion of pseudosclerotia with apothecia over time, the number of days elapsed in the germination chamber until this proportion attained $25 \%$ of $p_{\max }$ was identified for each chilling period. This percentile was used to summarize and compare the dynamics of apothecium emergence in populations of pseudosclerotia; it was considered less sensitive to extreme values than variables based on earlier events (i.e., the date that the first apothecium emerged) and more practical than indices based on later events (i.e., the date that $p_{\max }$ was reached).

TABLE 2. Results of a split-plot analysis of variance to determine the effects of chilling treatment and chilling period on the proportion of pseudosclerotia of Monilinia vaccinii-corymbosi that germinated or formed apothecia in the laboratory ${ }^{\mathrm{a}}$

\begin{tabular}{|c|c|c|c|c|c|c|c|}
\hline \multirow[b]{2}{*}{ Source } & \multirow[b]{2}{*}{ df } & \multicolumn{3}{|c|}{ Proportion of germinated pseudosclerotia } & \multicolumn{3}{|c|}{ Proportion of pseudosclerotia with apothecia } \\
\hline & & Mean Square & $F$ & $P>F$ & Mean Square & $F$ & $P>F$ \\
\hline Experiment (block) & 1 & 0.0024 & 0.15 & 0.7659 & 0.0012 & 0.14 & 0.7720 \\
\hline Chilling treatment (main plot) & 1 & 0.0034 & 0.21 & 0.7281 & 0.0002 & 0.02 & 0.9061 \\
\hline Chilling period (subplot) & 5 & 0.0200 & 10.80 & 0.0021 & 0.0110 & 7.64 & 0.0065 \\
\hline Chilling treatment $\times$ chilling period & 5 & 0.0016 & 0.88 & 0.5373 & 0.0005 & 0.33 & 0.8804 \\
\hline Subplot error & 8 & 0.0018 & - & - & 0.0014 & - & - \\
\hline
\end{tabular}

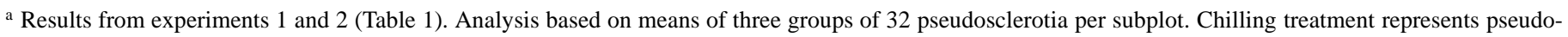
sclerotia buried in saturated sand or submerged in continuously aerated distilled water. Chilling applied for 0 , 336, 672, 1,008, or 1,344 h (experiment 1 ) and $0,96,336,672,1,008$, or 1,344 h (experiment 2). 
Field-laboratory experiment. Pseudosclerotia were collected from the ground in a rabbiteye blueberry planting in Bacon County in southern Georgia on 7 November 1997, 5 December 1997, and 15 January 1998 after they had received, respectively, 21,124 , and $429 \mathrm{~h}$ of natural chilling (experiment 3 ; Table 1). The number of heating degree-days (base $7.2^{\circ} \mathrm{C}$, referred to as "degree-days") received in the field prior to each collection date was determined based on air temperature measurements at a nearby agrometeorological station; accumulation of degree-days was initiated on the date when the first chill-hour was recorded (28 October). Pseudosclerotia were rinsed, placed in groups of 32 on sand kept at field capacity in pots, incubated in the germination chamber, and monitored and assessed as described above. The proportion of pseudosclerotia that germinated or formed apothecia was recorded for each pot, and means were computed based on three pots for each collection date.

Field experiments. Pseudosclerotia from early season cv. Climax and late season cv. Tifblue (chilling requirement 400 to $450 \mathrm{~h}$ and 600 to $800 \mathrm{~h}$, respectively) were collected in Murray County in northern Georgia on 8 October 1997 and 24 October 1998 (experiments 4 and 5, respectively; Table 1). At the time of their collection, the pseudosclerotia had received 26 chill-hours in 1997 and 34 chill-hours in 1998. Pseudosclerotia were rinsed as described above, placed in groups of 37 to 42 on a layer of washed sand beneath blueberry bushes in a research planting with no history of mummy berry disease on the University of Georgia campus, and covered with wire screen cages. Beginning in late winter in both years, the planting was sprinkler-irrigated with a fine mist at 1- to 4-day intervals to provide suitable soil moisture for carpogenic germination. Environmental conditions, including accumulation of chill-hours and degree-days, were measured at a nearby agrometeorological station. Pseudosclerotia were monitored and assessed twice a week for germination and apothecium emergence as described above. The proportion of germinated pseudosclerotia and of pseudosclerotia with apothecia was calculated for each group at each assessment date, and means were computed based on four groups per cultivar (six groups for cv. Tifblue in 1997). Kolmogorov-Smirnov tests (SAS Institute Inc., Cary, NC) were applied to determine whether the progress curves describing the two variables over time were significantly different for the two cultivars.

Model for apothecium emergence. The numbers of chill-hours $\left(c_{25}\right)$ and degree-days $\left(d_{25}\right)$ accumulated between the onset of chilling and the time at which the cumulative proportion of pseudosclerotia with apothecia attained $25 \%$ of $p_{\max }$ were calculated for each of the chilling periods in the five experiments described above. $d_{25}$ was plotted against $c_{25}$, and a hyperbola of the form $d_{25}=a \times b /\left(b+c_{25}\right)$, in which $a$ and $b$ are parameters, was fitted (SigmaPlot version 6.0; SPSS Science, Chicago). The equation describes an isoline for the 25th percentile of apothecium emergence for a range of chill-hour and degree-day combinations.

\section{RESULTS}

Laboratory experiments. The duration of chilling strongly affected the proportion of pseudosclerotia that subsequently germinated or formed apothecia (Fig. 1, Table 2). Pseudosclerotia receiving $\leq 130$ chill-hours showed very limited germination (Fig. 1A) and did not produce any apothecia (Fig. 1B) despite remaining in conditions favorable for germination for $>4$ months following chilling. With increasing chilling, both germination and apothecium production increased and attained a maximum at $\approx 700$ chill-hours. As chill-hours increased beyond this optimum, the incidence of germination and apothecium production was reduced. The ratio of the proportion of apothecium-producing pseudosclerotia to that of germinated pseudosclerotia also peaked at intermediate levels of chilling (Fig. 1C). Germination and apothecial emergence occurred more rapidly for pseudosclerotia that had received high levels of chilling than for those that had received lower levels of chilling (Fig. 2).
Field-laboratory experiment. In pseudosclerotia that had received 21 chill-hours in the field prior to being placed in the germination chamber, the incidence of germination remained very close to zero, and only one pseudosclerotium (out of 96 total) subsequently produced an apothecium (Fig. 3). By contrast, 36.5\% of the pseudosclerotia exposed to 124 chill-hours germinated, and $11.5 \%$ of the pseudosclerotia in this treatment produced apothecia. Nearly $60 \%$ of the pseudosclerotia exposed to 429 chill-hours in the field had already germinated at the time of collection, and this proportion remained relatively constant during incubation in the germination chamber; $38.5 \%$ of the pseudosclerotia in this treatment subsequently produced apothecia (Fig. 3).
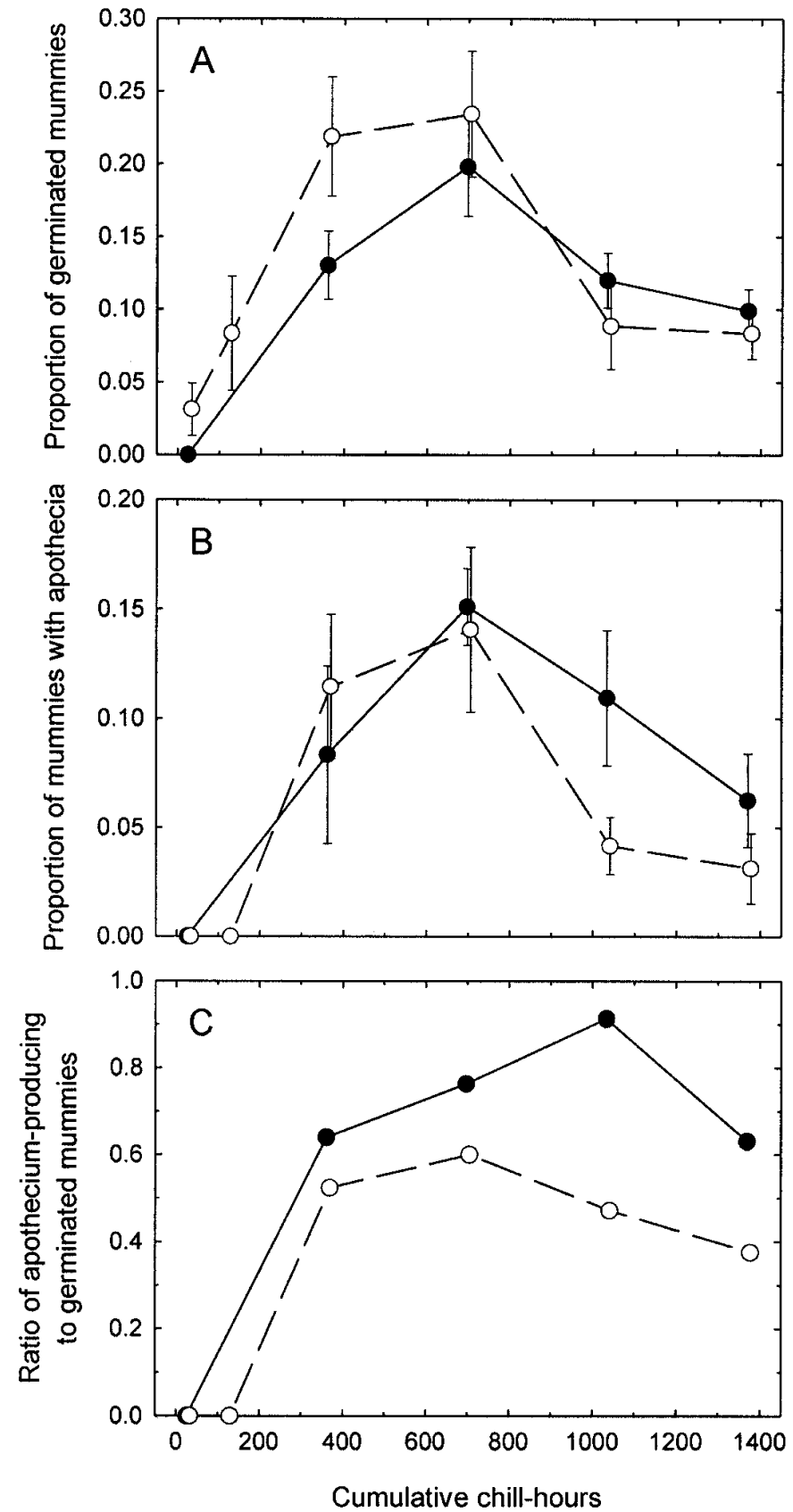

Fig. 1. Proportion of pseudosclerotia (mummies) of Monilinia vacciniicorymbosi that $\mathbf{A}$, germinated or $\mathbf{B}$, formed apothecia after exposure to various periods of chilling in the laboratory. $\mathbf{C}$, Ratio of the proportion of apothecium-producing pseudosclerotia to that of germinated pseudosclerotia for each chilling period. Pseudosclerotia were transferred to a germination chamber at the end of their respective chilling periods. Values are means and standard errors of six groups of 32 pseudosclerotia per treatment. Results of experiments $1(\bigcirc)$ and $2(\bigcirc)$ (Table 1$)$. 
Field experiments. Germination of pseudosclerotia and apothecium production after exposure to natural chilling and germination conditions in the field was initiated earlier and continued over a longer period in the first year (Fig. 4A and C) than in the second year (Fig. 4B and D). However, apothecium emergence attained $25 \%$ of $p_{\max }$ after similar chill-hour and degree-day totals in both years (Table 1). The incidence of germination and apothecium production was considerably greater in the second year than in the first year. In both years, most of the pseudosclerotia that germinated (Fig. 4A and B) subsequently produced apothecia (Fig. 4C and D).

Pseudosclerotia from early season cv. Climax and late season cv. Tifblue germinated and produced apothecia at approximately the same time (Fig. 4). When the progress curves for germination and apothecium emergence were compared with KolmogorovSmirnov tests, no significant differences were detected between the two cultivars (Table 3 ).

Model for apothecium emergence. Thermal time (expressed as cumulative chill-hours and degree-days) accounted for a large part of the variation in the timing of apothecium emergence across the five experiments, with fewer degree-days needed to reach $25 \%$ of $p_{\max }$ as the number of chill-hours increased (Fig. 5). The relationship between $d_{25}$ and $c_{25}$ was described by $d_{25}=1,032 \times$ $541.2 /\left(541.2+c_{25}\right)\left(P<0.0001, R^{2}=0.938\right)$.

\section{DISCUSSION}

The number of chill-hours accumulated during the conditioning period affected the subsequent incidence of carpogenic germination of pseudosclerotia of $M$. vaccinii-corymbosi. Whereas germination and apothecium production occurred over a wide range of chill-hours, the proportion of pseudosclerotia that germinated or formed apothecia was greatest after intermediate levels of chilling $(\approx 700$ chill-hours). Although there was evidence for a minimum chilling requirement for carpogenic germination, its exact magnitude could not be identified as, across all experiments, a few pseudosclerotia receiving very low chill-hour totals did germinate after accumulating a high number of degree-days. However, the observation that only one apothecium was produced on pseudosclerotia that received <34 chill-hours in the field-laboratory experiment, along with the requirement of at least 130 chill-hours for the production of apothecia in the two laboratory experiments,

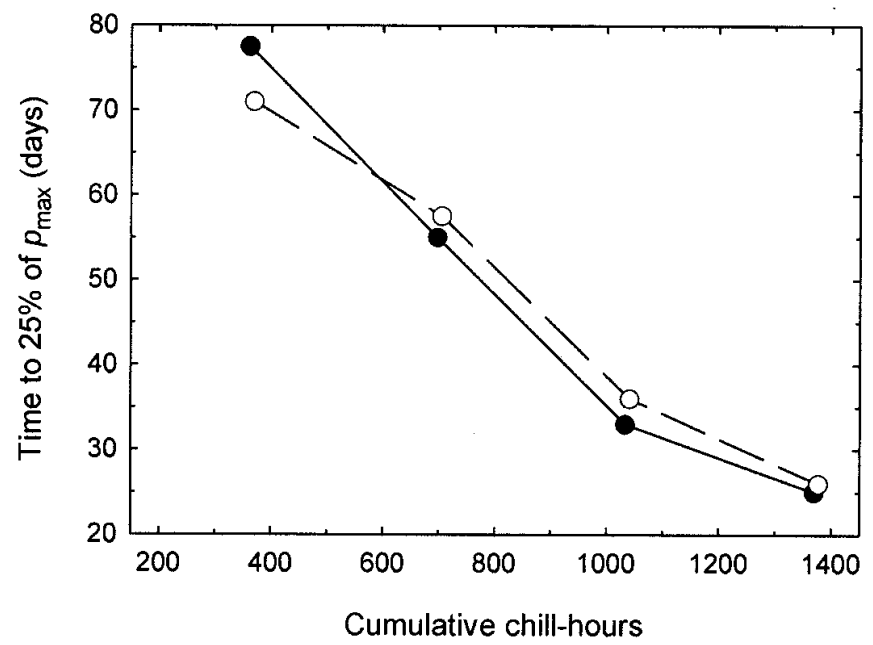

Fig. 2. Number of days elapsed in a germination chamber until the cumulative proportion of pseudosclerotia of Monilinia vaccinii-corymbosi with apothecia attained $25 \%$ of its maximum value $\left(p_{\max }\right)$ after exposure to various periods of chilling in the laboratory. Pseudosclerotia were transferred to the germination chamber at the end of their respective chilling periods. Values are means of six groups of 32 pseudosclerotia per treatment. Results of experiments $1(\bigcirc)$ and $2(\bigcirc)$ (Table 1$)$. does provide evidence for an absolute minimum chilling requirement for apothecium production that is considerably lower than the 900 to 1,200 chill-hour minimum determined in North Carolina (19) and that of 700 chill-hours in Washington State (5) for pseudosclerotia produced on highbush blueberry. Taken together, our results on minimum and optimum chilling requirements showed that populations of $M$. vaccinii-corymbosi from rabbiteye blueberry production regions in Georgia have adapted to germinate carpogenically in the low-chill environments characteristic of these regions, where chill-hour accumulation from 1 October through 15 February ranges from 600 to $800 \mathrm{~h}$ in normal winters and from 400 to $500 \mathrm{~h}$ in warm winters (25). In a broader context, the results support the hypothesis of successful adaptation of $M$. vaccinii-corymbosi to diverse environments (ranging from Nova Scotia to Washington State to southern Georgia) and to the chillhour requirements of the different host species grown in these environments $(5,14,16,19)$.

In addition to chill-hour accumulation during the conditioning period, other factors apparently affected the incidence of carpogenic germination of pseudosclerotia in this study. For example, the maximum incidence of germination was 13.8 and $42.9 \%$ in experiments 4 and 5 , respectively, both of which were carried out in the field in similar experimental conditions (soil type, soil moisture, and photoperiod) with similar chill-hour and degree-day totals. Differences in the levels of germination between the two experiments may have been due to differences in pseudosclerotial viability. In pseudosclerotia formed on rabbiteye blueberry, vi-
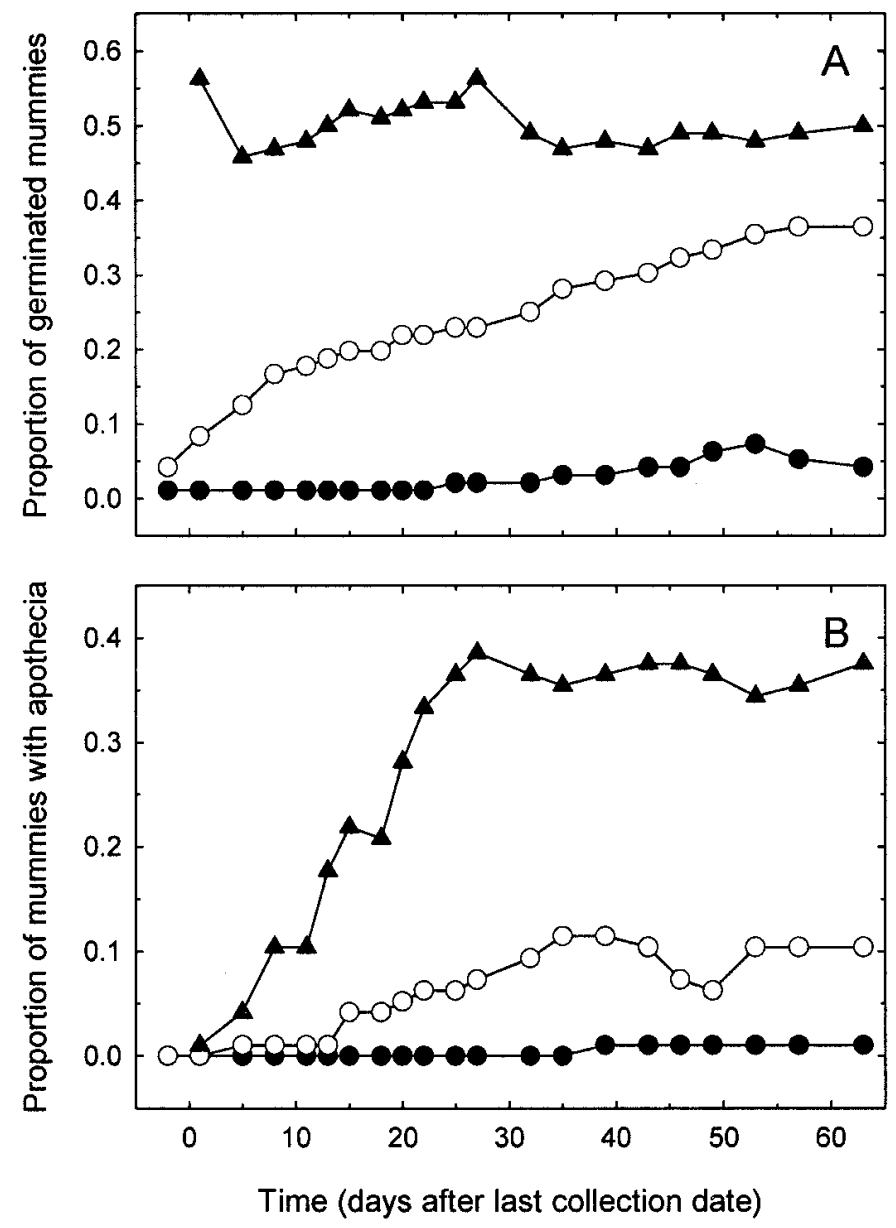

Fig. 3. Proportion of pseudosclerotia (mummies) of Monilinia vacciniicorymbosi that $\mathbf{A}$, germinated or $\mathbf{B}$, formed apothecia after exposure to natural chilling in the field for $21(\mathbf{O}), 124(\mathrm{O})$, and $429(\boldsymbol{A})$ chill-hours. Pseudosclerotia were transferred to a germination chamber in the laboratory at the end of their respective chilling periods. Values are means of three groups of 32 pseudosclerotia per treatment. Results of experiment 3 (Table 1). 
ability is strongly affected by pseudosclerotial maturity (characterized by the extent of fungal colonization of the fruit and the degree of melanization of the fungal tissue) at the time when infected fruit drop to the ground in early summer and by environmental conditions during the subsequent oversummering period (8). Because the pseudosclerotia used in the two experiments were collected in different years, year-to-year variations in viability, determined in part by environmental conditions prior to collection, could explain the variations in the incidence of germination between the two experiments.

The temporal dynamics of carpogenic germination were similar in populations of pseudosclerotia from early and late season cultivars of rabbiteye blueberry. This differs from the work of Lehman and Oudemans $(14,16)$ who described cultivar-specific adaptation in populations of $M$. vaccinii-corymbosi from highbush blueberry in New Jersey, whereby apothecia emerged earlier on pseudosclerotia from early season cultivars than on those from late season cultivars. The authors hypothesized that earlier bud break dates in the former cultivars provided sufficient selection pressure to lead to the evolution of earlier apothecium emergence in the pathogen. Highbush cultivars are generally grown in single-cultivar stands, thus infection of flowers occurs via conidia produced on blighted vegetative tissue of the same cultivar. Because of the long period that the bushes remain in production ( $>30$ years), cultivar-specific host-pathogen coevolution is plausible in this production system. By contrast, due to limited self-fertility, rabbiteye cultivars are always planted in mixed stands (2), where rows of two or more cultivars are alternated. These cultivars often differ in the onset of vegetative bud break, which, along with a generally more protracted period of bud development, would suggest a much reduced selection pressure for cultivar-specific adaptations in pathogen phenology. This is similar to observations by Lehman and Oudemans (16) where pseudosclerotia collected from a mixed stand of highbush blueberry cultivars were intermediate in timing of apothecium emergence compared with those collected from single-cultivar stands of early and late season cultivars.

TABLE 3. Results of Kolmogorov-Smirnov tests to determine whether the progress curves describing the proportion of pseudosclerotia of Monilinia vaccinii-corymbosi that germinated or formed apothecia in the field were significantly different for cvs. Climax (early season) and Tifblue (late season) ${ }^{\mathrm{a}}$

\begin{tabular}{lccc}
\hline Variable & Year & $n^{\mathrm{b}}$ & $P$ \\
\hline Germinated pseudosclerotia & $1997-1998$ & 17 & 0.1120 \\
& $1998-1999$ & 11 & 0.8079 \\
Pseudosclerotia with apothecia & $1997-1998$ & 12 & 0.5176 \\
& $1998-1999$ & 6 & 0.8928 \\
\hline
\end{tabular}

${ }^{a}$ Results from experiments 4 and 5 .

b Observations at the onset of the experiments, when proportions were zero for both cultivars, were excluded from the analysis.

\section{Experiment $4(1997-98)$}
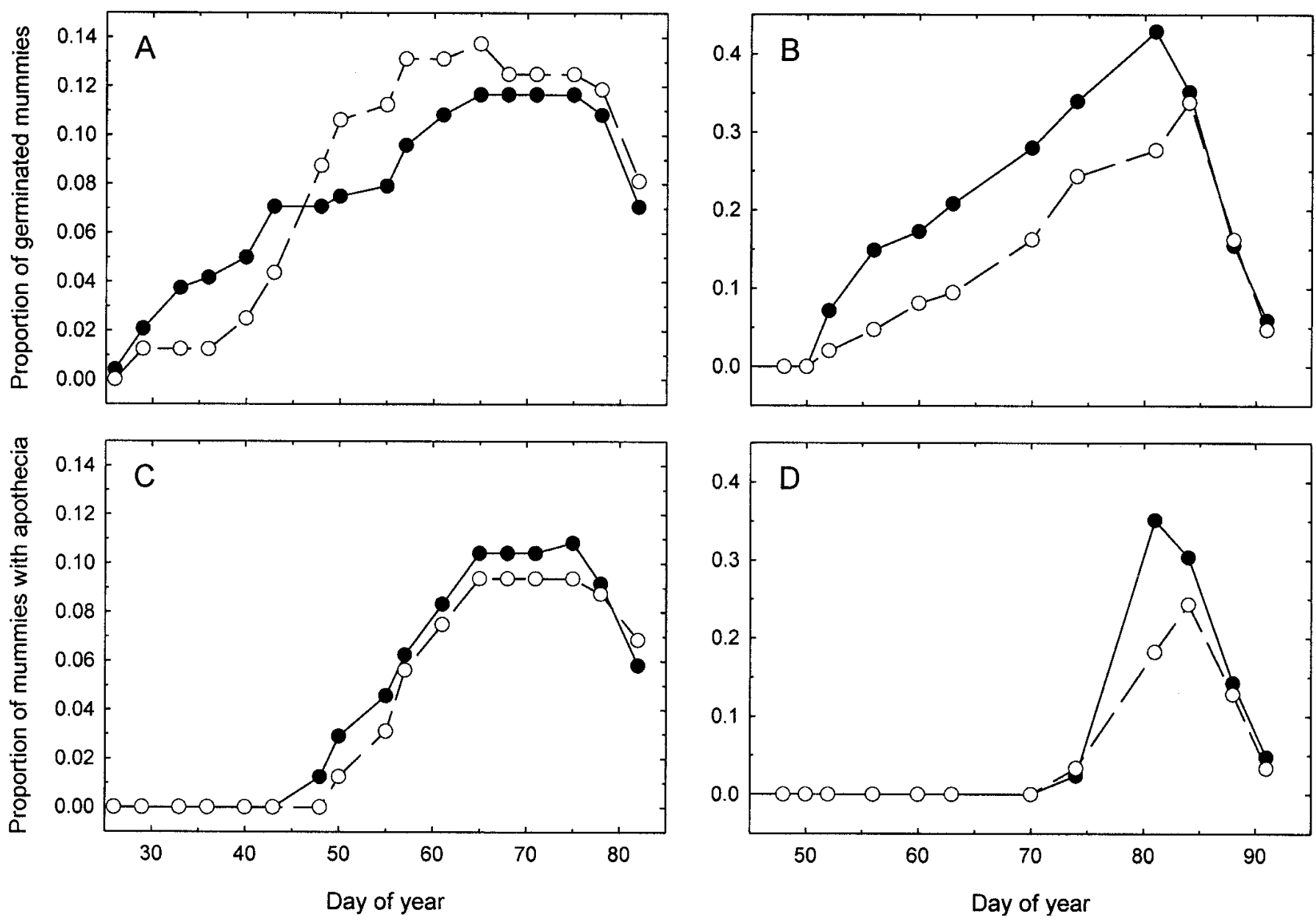

Fig. 4. Proportion of pseudosclerotia (mummies) of Monilinia vaccinii-corymbosi that $\mathbf{A}$ and $\mathbf{B}$, germinated or $\mathbf{C}$ and $\mathbf{D}$, formed apothecia after exposure to natural chilling and germination conditions in the field. Pseudosclerotia were from early season rabbiteye blueberry cv. Climax (@) and from late-season cv. Tifblue $(\bigcirc)$. Values are means of four to six groups of 37 to 42 pseudosclerotia per treatment. Results of experiments 4 and 5 (Table 1). 


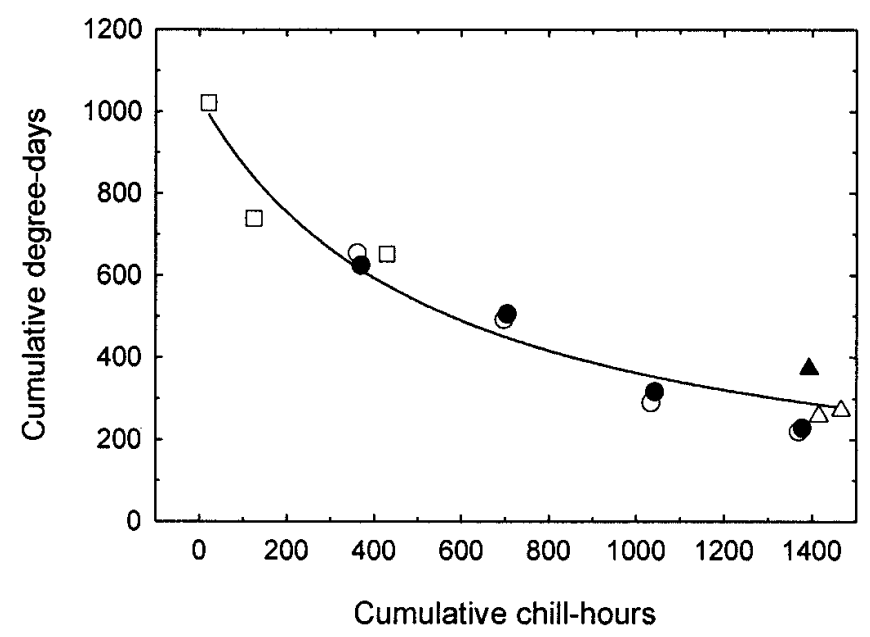

Fig. 5. Relationship between the number of chill-hours and heating degreedays accumulated until the cumulative proportion of pseudosclerotia of Monilinia vaccinii-corymbosi with apothecia attained $25 \%$ of its maximum value for each treatment. Treatments primarily consisted of different periods of chilling in the laboratory or in the field. Results of experiments $1(\bigcirc), 2$ $(\boldsymbol{O}), 3(\square), 4(\Delta)$, and $5(\boldsymbol{\Delta})$ (Table 1). The regression line is a two-parameter hyperbola.

The rate of carpogenic germination of pseudosclerotia of $M$. vaccinii-corymbosi was strongly affected by interactions between the number of chill-hours and degree-days accumulated during the conditioning and germination periods. Pseudosclerotia exposed to prolonged chilling periods, once transferred to suitable conditions, germinated and produced apothecia more rapidly (after fewer degree-days had accumulated) than those exposed to shorter chilling periods. This suggests that high numbers of chill-hours can compensate for low numbers of degree-days and vice versa. Thus, pseudosclerotia are adapted to germinate and form apothecia following cold winters (high chill-hours, low degree-days) as well as warm winters (low chill-hours, high degree-days). Interestingly, this relationship applied to experiments in which conditioning and germination treatments were imposed consecutively in discrete periods (i.e., chilling at a constant temperature followed by germination at a higher constant temperature; experiments 1 and 2) and to those in which the two treatments occurred concurrently in fluctuating temperatures (experiments 4 and 5).

Models incorporating both chilling and heat requirements have been used previously to describe flowering dynamics in several fruit species $(7,24)$, including blueberries $(20)$; however, they have not been applied to quantify the germination response to temperature in plant-pathogenic fungi. In the present study, a combined chill-hour and degree-day model adequately described apothecium emergence in data sets obtained with pseudosclerotia from different cultivars, collected at distant locations in Georgia, and exposed to different (natural vs. laboratory) conditioning and germination treatments over a wide range of chill-hours $(21$ to 1,465$)$ and degree-days (202 to 1,022). The model predicts the number of chill-hours and degree-days accumulated until the proportion of pseudosclerotia with apothecia attained $25 \%$ of $p_{\max }$. The choice of this variable to summarize the dynamics of apothecium emergence was based primarily on statistical and practical considerations as discussed above. This variable alone could be used to decide upon the optimal timing of a scouting program for the presence of apothecia. In concert with additional variables such as inoculum density (which could be determined via scouting), host phenology $(10,15)$, and weather (11), it could serve as a key component for predicting the risk of primary infection.

It is important to note that all experiments reported in this paper were carried out in conditions of high soil moisture. It is well established that soil moisture significantly affects carpogenic germi- nation in $M$. vaccinii-corymbosi $(4,18)$ and closely related discomycetes $(4,21)$. Indeed, Milholland (18) observed that pseudosclerotia from northern highbush blueberry readily germinated and produced apothecia when placed on soil held at $81 \%$ of field capacity, whereas no germination occurred at $35 \%$ of field capacity. Because apothecium development is reduced or delayed in suboptimal soil moisture conditions, many apothecia in commercial blueberry plantings, particularly those without supplemental irrigation, are likely to emerge later than suggested by the model in Figure 5. Thus, the model may be most useful in providing a worst-case scenario for irrigated fields and for low-lying, wet sites in nonirrigated fields where soil moisture is more likely to be consistently favorable for carpogenic germination (17). In a broader context, it may be useful as a tool for "negative prognosis" (31) in predicting the interval before which apothecia are unlikely to emerge. This information should be useful for better timing of field scouting programs for apothecia to aid in management decisions against primary infection by $M$. vaccinii-corymbosi.

\section{ACKNOWLEDGMENTS}

This study was funded, in part, by the Michigan Blueberry Growers Association and the University of Georgia Research Foundation. We thank A. Castro for technical support, D. Stanaland for help with the collection efforts in southern Georgia, and J. Lehman for comments on the manuscript.

\section{LITERATURE CITED}

1. Ahlers, D. 1989. Integrierter Pflanzenschutz bei Pilzkrankheiten in Winterraps. Gesunde Pflanzen 41:306-311.

2. Austin, M. E. 1994. Rabbiteye Blueberries. Development, Production, and Marketing. Agscience Inc., Auburndale, FL.

3. Batra, L. R. 1983. Monilinia vaccinii-corymbosi (Sclerotiniaceae): Its biology on blueberry and comparison with related species. Mycologia 75:131-152.

4. Batra, L. R. 1991. World Species of Monilinia (Fungi): Their Ecology, Biosystematics and Control. J. Cramer, Berlin.

5. Bristow, P. R. 1979. Mummy berry disease: Mummy germination. Pages 163-169 in: Proc. North Am. Blueberry Res. Workers Conf., 4th. J. N. Moore, ed. University of Arkansas, Fayetteville.

6. Cline, W. O., and Milholland, R. D. 1995. Diseases of blueberry fruit at harvest in North Carolina. J. Small Fruit Vitic. 3:219-225.

7. Couvillon, G. A., and Erez, A. 1985. Influence of prolonged exposure to chilling temperatures on bud break and heat requirement for bloom of several fruit species. J. Am. Soc. Hortic. Sci. 110:47-50.

8. Cox, K. D., and Scherm, H. 2000. Oversummering success of pseudosclerotia of Monilinia vaccinii-corymbosi in relation to maturity and soil surface environment. (Abstr.) Phytopathology 90(suppl.):S17.

9. Dillard, H. R., Ludwig, J. W., and Hunter, J. E. 1995. Conditioning sclerotia of Sclerotinia sclerotiorum for carpogenic germination. Plant Dis. 79:411-415.

10. Ehlenfeldt, M. K., Stretch, A. W., and Lehman, J. S. 1997. Shoot length affects susceptibility to mummy berry blight within highbush blueberry cultivars. HortScience 32:884-887.

11. Hildebrand, P. D., and Braun, P. G. 1991. Factors affecting infection of lowbush blueberry by ascospores of Monilinia vaccinii-corymbosi. Can. J. Plant Pathol. 13:232-240.

12. Hildebrand, P. D., Milholland, R. D., and Stretch, A. W. 1995. Mummy berry. Pages 11-12 in: Compendium of Blueberry and Cranberry Diseases. F. L. Caruso and D. C. Ramsdell, eds. The American Phytopathological Society, St. Paul, MN.

13. Hoogenboom, G. 1996. The Georgia Automated Environmental Network. Pages 343-346 in: Preprints 22nd Conf. Agric. Forest Meteorol./12th. Conf. Biometeorol. Aerobiol., The American Meteorological Society, Boston.

14. Lehman, J. S., and Oudemans, P. V. 1997. Phenology of apothecium production in populations of Monilinia vaccinii-corymbosi from earlyand late-maturing cultivars. Phytopathology 87:218-223.

15. Lehman, J. S., and Oudemans, P. V. 1997. Phenology of the mummy berry fungus and its blueberry host: Implications for resistance breeding. Acta Hortic. 446:287-292.

16. Lehman, J. S., and Oudemans, P. V. 2000. Variation and heritability of phenology in the fungus Monilinia vaccinii-corymbosi on blueberry. Phytopathology 90:390-395. 
17. Lockhart, C. L., Delbridge, R. W., and McIsaac, D. 1983. Observations on Monilinia twig and blossom blight of the lowbush blueberry in the Maritime Provinces. Can. Plant Dis. Surv. 63:31-34.

18. Milholland, R. D. 1974. Factors affecting apothecium development of Monilinia vaccinii-corymbosi from mummified highbush blueberry fruit. Phytopathology 64:296-300.

19. Milholland, R. D. 1977. Sclerotium germination and histopathology of Monilinia vaccinii-corymbosi on highbush blueberry. Phytopathology 67:848-854.

20. NeSmith, D. S., and Bridges, D. C. 1992. Modeling chilling influence on cumulative flowering: a case study using 'Tifblue' rabbiteye blueberry. J. Am. Soc. Hortic. Sci. 117:698-702.

21. Phillips, A. J. L. 1987. Carpogenic germination of sclerotia of Sclerotinia sclerotiorum: A review. Phytophylactica 19:279-283.

22. Ramsdell, D. C., Nelson, J. W., and Myers, R. L. 1974. An epidemiological study of mummy berry disease of highbush blueberry. Phytopathology 64:222-228.

23. Ramsdell, D. C., Nelson, J. W., and Myers, R. L. 1975. Mummy berry disease of highbush blueberry: Epidemiology and control. Phytopathology 65:229-232.

24. Richardson, E. A., Seeley, S. D., and Walker, D. R. 1974. A model for estimating the completion of rest for 'Redhaven' and 'Elberta' peach trees. HortScience 9:331-332.

25. Sanders, C. G. 1976. Climatic chilling in Georgia. Geor. Agric. Res, 18:19-21.

26. Savelle, A. T., and Scherm, H. 1998. Predicting germination and apothecium formation in Monilinia vaccinii-corymbosi. Pages 129-134 in: Proc. North Am. Blueberry Conf., 8th. Wilmington, NC.

27. Scherm, H., and Copes, W. E. 1999. Evaluation of methods to detect fruit infected by Monilinia vaccinii-corymbosi in mechanically harvested rabbiteye blueberry. Plant Dis. 83:799-805.

28. Scherm, H., and Savelle, A. T. 1998. Predicting apothecium emergence in Monilinia vaccinii-corymbosi. (Abstr.) Phytopathology 88(suppl.):S79.

29. Shinners, T. C., and Olson, A. R. 1996. The gynoecial infection pathway of Monilinia vaccinii-corymbosi in lowbush blueberry (Vaccinium angustifolium). Can. J. Plant Sci. 76:493-497.

30. Shoemaker, J. S. 1978. Small Fruit Culture. 5th ed. AVI Publishing Co., Westport, CT.

31. Ullrich, J., and Schrödter, H. 1966. Das Problem der Vorhersage des Auftretens der Kartoffelkrautfäule (Phytophthora infestans) und die Möglichkeit seiner Lösung durch eine Negativprognose. Nachrichtenbl. Dtsch. Pflanzenschutzdienst. 18:33-40. 